\title{
绿色建筑在规划设计中的问题及解决措施
}

陈宝治

中北工程设计咨询有限公司

DOI:10.18686/bd.v2i9.1647

[摘 要] 可持续发展已经成为当前生态建设和发展过程中十分关键的问题, 城市发展中绿色建筑的出现主要是为了树立 城市形象, 加强城市的吸引力, 改善城市居民的居住环境。而绿色建筑规划设计虽然得到了显著的发展, 但是其依然存在着 较为明显的问题,需要采取科学有效的解决措施加以完善。

[关键词] 绿色建筑; 规划; 问题; 措施

\section{1 绿色建筑的发展现状}

当前,我国绿色建筑发展迅猛,且建筑行业的耗能也呈 现出日趋走高的趋势。我国城市人口的不断增多虽然促进 了建筑行业的建设与发展, 但建筑行业发展的过程中也消 耗了大量的资源, 影响了我国生态建设水平。因此在当今的 建筑行业发展中,绿色建筑成为发展的主流。但是从当前的 实际情况来看, 我国绿色建筑的发展主要采用政策推动的 方式, 人们在思想观念上还存在着一定的不足。

\section{2 绿色建筑在城市规划中的作用}

2.1 转变城市建设模式

当前, 城市的发展伴随着较为严重的生态破坏, 绿色建 筑是建筑环保当中非常重要的一种理念, 其在产业循环、资 源利用和文化传播等多个方面与可持续发展理念充分融 合, 转变了以往资源指向型的城市建设方式。在城市规划和 建设的过程中, 积极利用与发展绿色建筑能够十分有效地 推动城市生态建设, 同时促进城市的低碳发展, 且在城市文 化建设中也能够合理地融入循环发展的理念, 并以绿色建 筑为基础,推动城市经济快速进步。

2.2 促进节能减排目标的实现

现阶段,在城市规划中,绿色建筑已经成为了主要的发 展趋势。但是当前我国的绿色建筑数量较少, 所以规划人员 应结合实际情况, 规划出具有地区特色的绿色建筑, 为周边 带去积极的影响, 带动整个乃至于周边地区的建设与发展, 从而更好地实现绿色建筑建设的整体目标, 不断提升我国 新兴产业的核心竞争力, 而且该规划也可有效应对未来市 场上的科技竞争,并为其提供雄厚的技术支持。

\section{3 绿色建筑规划设计中的问题}

3.1 受短期利益影响较为严重

在城市规划建设中, 若片面追求经济利益和销售效率 而不重视其生态效益就, 会对城市的发展构成十分不利的 影响, 因为城市生态研究只是城市规划设计中的参考, 没有 对城市生态安全系统和生态系统的容量及承载力进行科学 分析。建筑规划的科学性明显不足, 而在城市和乡村当中都 有建筑, 因此绿色建筑的发展失去了有利的环境。另外, 在 城市规划设计中片面重视形象工程, 将城市规划为一个具
有观赏性和展览性功能的场所, 市政办公楼通常坐落于大 规模的广场中, 广场的周围设有博物馆、图书馆和大型医院 等场所。这种规划布局形式虽然很好地展现了城市的形象, 但是却没有充分考虑到城市建设的基本要求。加之在建筑 设计中也多采用新颖奇特的造型, 富丽堂皇的装饰以及超 大的空间都成为了展示城市实力的重要元素, 而这种规划 设计势必会造成空间和材料的大量浪费。不但需要投入较 高的建设成本,还会消耗大量的能源。

此外,建筑应用的过程中大多采用人工照明、空调等多 种耗能较大的方式来保证其正常运转, 且很多场馆并未得 到有效利用, 而在场馆运营的过程中也需要巨大的成本投 人。基于此,城市规划和建设工作中,应充分保证城市资源 的优化配置以及城市的科学建设与发展。若城市资源集中 度过高, 就会出现人流聚集, 交通拥堵等现象, 影响城市环 境质量。

\section{2 绿色建筑理解不准确}

3.2 .1 设计只能满足基本要求

很多人对绿色建筑的理解都不是十分准确, 认为绿色 建筑就是为了通过相关部门的检查和审核而做的一系列工 作, 因此在绿色建筑的设计中, 通常仅仅只能满足最为基本 的要求, 没有充分了解建筑及周边的环境状况, 而且也没有 关注环境和生态的变化, 进而出现了设计中盲目使用施工 材料,出现严重环境污染等问题。

3.2.2 环保技术利用不科学

片面重视绿色建筑中高新科技的应用, 随意使用多种 环保技术, 进而使建筑造价明显提高, 建筑运营的成本也会 有所上升。以太阳能光伏电技术为例, 这一技术的应用需要 近 100 年的时间才能收回经营成本。再者, 没有充分了解当 地的环境情况就引进国外双层玻璃幕墙技术, 从而使内部 累积大量灰尘, 不利于建筑的整洁, 综合效果也因此受到了 较大的影响。此外在城市当中供热相对较为充足的地段应 用热原技术,这一方面影响了施工的效果,另一方面也降低 了工程的经济效益,使方案设计中,很多环保技术都无法充 分体现其作用与价值。

3.2.3 无法合理引人外来技术 
一些建筑设计师在进行建筑设计工作时，没有充分地 利用传统建筑中绿色设计的理念和要素, 认为国外的最新 方法环保性最强, 这也加大了外来技术引用的盲目性, 大大 提高了建筑设计和建设的成本。而建筑工程相关标准当中, 已经对绿色建筑评价进行了详细的规定, 其需要以建筑整 个生命周期为考察范围, 并且还应积极带动节能材料和再 生材料的广泛应用, 而上述建筑设计理念显然不能实现绿 色建筑施工目的。

\section{4 改善我国绿色建筑规划设计问题的措施}

4.1 建立科学的规划设计评价机制

建立并完善城乡规划和建筑设计评价体系, 增加对生 态和环境保护的法律法规建设,要有科学的量化指标。规划 和建筑设计是涉及到多系统、多学科的课题, 需要对项目进 行多方论证, 充分尊重专家学者意见, 要避免过多的行政干 预。而且环境评估报告不能走形式, 应在以后的实施过程中 逐条落实,并形成验收和监督机制。

创建科学完善的城乡规划以及建筑设计评价机制, 加 大生态和环境保护法律法规制定的力度, 同时科学选择量 化指标。城市规划和建筑设计中需要应用到很多方面的知 识, 必须要对项目进行科学的验证, 并积极听取专家学者的 意见和建议, 防止规划设计的过程中有过多行政干预的参 与。此外,环境评估报告应详实、具体, 同时要在日后的工作 中积极落实, 这样才能更好地发挥其积极作用, 构建更为科 学和完善的监督机制。

4.2 加强技术人员的专业培训

在日常工作中, 可采取有效措施对规划和设计人员开 展专业的绿色建筑培训工作, 从而有效提升建工作人员在 绿色建筑设计方面的知识储备, 提高其设计与规划能力, 或 者也可帮助工作人员创立科学的生态系统观念, 让其对科 学解决环境问题的重要性建立正确的认识。

4.3 加大基础性研究的力度

对建筑设计进行科学指导, 从而优化我国建筑材料的 科技水平, 改变传统的发展模式, 同时积极借鉴和引进新型 的环保材料, 进而能够用科技的力量来带动绿色建筑设计 的发展, 提高建筑的耐久性, 推动建筑行业的可持续发展。

4.4 实施建筑开发商终身责任或保险机制

积极引导开发商提供更加优质的建筑产品, 并不断提 高建筑设计的质量和水平, 减少能源消耗和环境污染, 在加 强建筑性能、延长建筑寿命的同时, 还要使材料供应商也能 延长材料质保的期限。

4.5 积极实施总承包责任制
在设计中应组织建筑、结构、机电以及室内设计等多个 设计团队, 对系统进行科学设计, 提出科学的设计方案, 以 此保证建筑多个子系统之间能够平稳运行, 减少建筑设计 中的问题与不足, 实现产业化和工业化发展, 这样才能在整 个建筑周期内降低成本和能耗。

\section{6 建立科学的建筑节能评估和检测协调机制}

在绿色建筑的设计中, 应针对既有的建筑节能评估, 创 建科学的协调机制, 对无法满足建筑节能要求的工程予以 督促, 除此之外还要请专业的设计人员给出科学完备的整 改方案。

\section{5 发展方向及趋势}

当前, 可持续发展在诸多行业的建设与发展中都占据 着十分重要的位置, 绿色建筑设计理念也逐渐成为人们关 注的焦点。绿色建筑理念当中主要有节约能源、节约资源和 回归自然等多种理念, 绿色建筑在设计的过程中也应充分 体现其节能的优势。如可合理利用太阳能, 减少采暖及空调 系统的应用,一方面可有效减少环境污染问题。另一方面还 可十分有效地节约能源, 为住户提供更加优良的居住环境。

另外绿色建筑设计人员需在建筑设计期间, 积极学习 新的知识和理念, 使绿色建筑与周围环境充分融合。此外还 应积极了解并掌握当地的居住环境以及周边的资源及环境 特征, 将其合理地应用于绿色建筑的设计环节, 这样既减少 了资源浪费, 也营造出了更好的城市环境。而且当前人们对 环境问题日益重视, 这也成为了绿色建筑得以发展的重要 条件。

\section{6 结束语}

绿色建筑设计中需充分体现人与自然环境之间的关 系, 并保证在整个建筑生命周期内, 在满足人对建筑使用功 能和其他功能要求的同时, 也能更好地降低资源的消耗, 确 保其经济的科学性及合理性, 降低其对环境所产生的不利 影响。又因为当前我国绿色建筑发展水平日益提高, 绿色建 筑设计的研究也日益深人, 所以在这一背景下, 有关人员需 要对建筑设计实行全方位创新, 从而带动建筑行业的平稳 发展。

[参考文献]

[1]武颂东.绿色建筑在规划设计中的问题及解决措施 探讨 [J].建筑知识,2017,37(12):96.

[2]郭巍.城市绿色建筑规划设计存在问题及解决对策 [J].建材与装饰,2016,(11):105-106.

[3]杨亚红. 绿色建筑在规划设计中的问题及解决措施 [J].住宅与房地产,2016,(33):63-64. 